\title{
Educação como adaptação: \\ a experiência segundo John Dewey
}

\section{Professor da Universidade do Estado de Santa Catarina (UDESC)}

\section{Resumo}

John Dewey desenvolve uma filosofia da educação fortemente marcada pelo método experimental de investigação e pela adoção da atitude naturalista em filosofia. Neste sentido, sua concepção do ser humano e da sociedade tem suas bases na noção mais ampla de transmissão da vida, em um ambiente social, por meio da comunicação de hábitos, crenças e valores. O caso mais específico deste processo da vida é a educação, pela qual a experiência de um indivíduo ou cultura se renovam e se modificam. Argumenta-se que um dos fatores fundamentais na educação é a necessidade de adaptação do indivíduo ao ambiente. A fim de que se possa incrementar e ampliar o sucesso de processos educativos, seja por procedimentos informais ou formais, é preciso ter em conta o tipo de experiência envolvida, e os efeitos desta experiência na adaptação do sujeito da educação ao seu ambiente. Sem o que, a educação não realizaria o efeito para o qual é designada.

Palavras-chave: educação; adaptação; Dewey.

\begin{abstract}
John Dewey has developed a philosophy of education strongly marked by the use of experimental methods and the adoption of the naturalized philosophical attitude. In this sense, his conception of the human being and society bears in the wide notion of life as transmission, in a social environment, by means of communication of habits, beliefs and values. The most specific case of this living process is education, by wich experience of an individual or culture renew and modifies itself. It is argued that one of the fundamental aspects in education is the need of fitness of the individual to this environment. In a way that makes possible to increase and enlarge the success of educational processes, either by informal or formal procedures, we need to have in mind the kind of experience involved, and the effects of this experience in adaptation of the subject of education, to his or her environment. Without this, education should not make the effect by wich it is designed.
\end{abstract}

Keywords: education; adaptation; Dewey. 


\section{Introdução}

$\mathbf{J}$

ohn Dewey é o mais produtivo e um dos mais conhecidos pensadores do século XX, por seu trabalho nas áreas da epistemologia, da moral e da política. É especialmente conhecido como pensador da educação, devido ao papel central que este tema possui na sua concepção do ser humano e da sociedade.

A presente discussão tem a intenção de desenvolver alguns comentários acerca da idéia de Dewey de que a educação é uma estrutura que promove a adaptação dos indivíduos ao ambiente em que estão inseridos. A educação é adaptativa, mesmo no sentido biológico do termo, que se liga a processos evolutivos. Correlacionada a esta visão adaptativa da educação, encontra-se a concepção de que a própria vida social constitui um ambiente sujeito aos efeitos do processo evolutivo. A vida social é composta de todos os significados, conhecimentos, hábitos e valores da conduta humana, transmissíveis pela comunicação. A maneira como estas duas teses (a de que a vida social evolui, e a de que a educação tem função adaptativa) são consideradas e tratadas por Dewey em sua filosofia da educação é o objeto ao qual este trabalho espera dar tratamento investigativo.

A questão que se espera responder, dentro do domínio teórico assim delimitado, pode ser expressa pela pergunta: que tipo de estratégia argumentativa Dewey utiliza, ao adotar o ponto de vista da educação como adaptação, socialmente estabelecida, dos indivíduos a seu ambiente social? Esperase discutir a questão em seu aspecto epistemológico, mostrando que a adoção do horizonte evolutivo, por parte de Dewey, é uma forma relativamente bem-sucedida de fornecer um fundamento conceitual, uma base, um alicerce à sua filosofia da educação, em diálogo constante com os outros temas de seu pensamento, e com descobertas, métodos e questionamentos que têm ocupado os pensadores na contemporaneidade.

A fim de atingir os objetivos propostos, segue-se, basicamente, a trilha aberta pela hipótese naturalista na interpretação da filosofia de Dewey, e do assunto aqui abordado. Isso aproxima as questões que Dewey se propõe e 
as respostas que indica, das questões e das respostas de outros autores, seus antecessores, como Charles Peirce, William James e, notadamente, Charles Darwin. Bem como de autores posteriores a ele, como W. Quine e Daniel Dennett.

O que se obtém ao discutir o pensamento de Dewey nestes termos é a compreensão do efetivo alcance desta filosofia para esclarecer e explicar aspectos relevantes do complexo conjunto de fenômenos, dificilmente captado em umas poucas palavras, que é a educação. É possível chegar-se, assim, a refletir sobre o conceito de evolução aplicado à cultura humana, mostrando que um dos mecanismos deste processo de evolução, mas não o único, é a ação intencional de transmissão de hábitos, crenças e valores, por meio dos processos sucessivamente mais sofisticados de comunicação. Esta transmissão é educação, numa das acepções do termo.

Dewey procura utilizar em sua filosofia as realizações e métodos provenientes das ciências modernas, num diálogo e numa investigação que pretende atender às demandas de explicação a respeito de um ambiente cultural cujo fator de modificação evolutiva cresce em aceleração cada vez mais alta. Por isso sua filosofia acaba se apresentando como um discurso bastante diversificado, tanto em métodos como em conceitos. Entretanto, há um tema unificador de toda a atitude teórica de Dewey, que integra suas reflexões nos diversos assuntos a que se dedicou, em um todo coerente e sistematizado. Este tema unificador pode ser descrito como a atitude naturalista.

\section{O naturalismo experimental de Dewey}

O naturalista é o investigador que considera os fenômenos como partes de uma estrutura integrada de eventos e regularidades, que recebe o nome de "natureza". A natureza é, de modo geral, o que pode vir a ser objeto da experiência de um indivíduo. Por isso, o método experimental de investigação é considerado o mais adequado para descrever e explicar a natureza. Quando se diz "natureza", entenda-se o ser humano incluído como uma parte 
dela, assim como as coisas que o ser humano faz, como suas funções tais como a linguagem, a cultura e a mentalidade. Segundo Dewey,

a experiência apresenta-se a si própria como o método, o único método, para atingir a natureza, penetrar seus segredos, e onde a natureza revelada empiricamente [...] aprofunda, enriquece e dirige o desenvolvimento posterior da experiência (Dewey, 1974, p. 161).

Sob este ponto de vista fica difícil imaginar o que poderia estar fora da natureza, sem estar automaticamente fora do campo daquilo a respeito do qual se pode falar, ou do que pode ser objeto de uma experiência.

Segundo Santayana, em seu artigo "Dewey's Naturalistic Metaphisics": "Seria difícil encontrar um filósofo para quem o naturalismo, assim concebido, é tão inveterado como em Dewey" (Santayana, 1939, p. 246247). Por isso é que se toma a sério aqui a postura naturalista como fundamento da filosofia deste autor. Não se trata de afirmar que a leitura naturalista seja apenas uma das leituras possíveis da filosofia de Dewey. Mais que isso, o naturalismo é considerado o próprio âmago desta filosofia, seu princípio condutor mais constante e uniforme. Sabe-se que o termo "natural" ou mesmo "naturalismo" têm sido, ao longo do pensamento moderno, utilizados de diferentes maneiras. Entretanto, o sentido apropriado deste termo no pensamento de Dewey não deve ser confundido. Naturalismo para Dewey, conforme já dissemos, trata de considerar como natureza o que pode ser estudado pelo método experimental. Isso tem como implicação que, "para o naturalista, nada pode ser substancial ou eficaz no pensamento, exceto seus órgãos e instrumentos, como cérebros, treinamento, palavras e livros" (Santayana, 1939, p. 249). Assim, o naturalista recusa-se a fazer especulações ou suposições quanto a qualquer evento ou regularidade que não seja objeto da experiência efetiva. Deve-se, ainda, entender o naturalismo tendo em conta que as características do ser humano são resultantes de pressões ambientais em um longo processo de evolução, e que a sociedade, a cultura, a linguagem e a educação, podem ser adequadamente descritas por meio de conceitos provenientes desta atitude metodológica. 
Acerca disso, Jerome Popp, em seu livro Evoluton's First Philosopher, afirma que "Dewey foi o primeiro filósofo a extrair completamente o significado das mudanças exigidas pelo que seria posteriormente visto como uma adequada explicação científica" (Popp, 2007, p. 4). Popp, em seu livro, procura argumentar a favor de uma linha interpretativa que dá a mais intensa tonalidade ao naturalismo de Dewey. Um dos recursos de que se vale para isso é a comparação do seu pensamento com o de autores mais atuais, principalmente de inclinação darwiniana, como Daniel Dennett e Richard Dawkins. É um projeto ousado, mas que tem como motivação esclarecer ao máximo o sentido da consideração naturalista dos problemas filosóficos. Esta atitude é o sinal de que os métodos e hipóteses das ciências empíricas, seu modo rigoroso e ao mesmo tempo imaginativo de explicar o mundo é bem vindo como um novo integrante para a explicação de questões da filosofia e da teoria da educação.

Ao invés de buscar fundamentos absolutos e ideais, o pensador naturalista pretende fornecer explicações plausíveis para problemas como o da aprendizagem, da aquisição da linguagem, da formação de hábitos de pensamento, ou o de conduta social, com base em princípios baseados numa consideração mais prática e experimental dos fenômenos. Claro que isto não implica em negar o caráter simbólico das instituições culturais, nem recair em alguma espécie de determinismo biológico.

A velha busca por princípios e fundamentos formais que fossem anteriores logicamente, e condicionantes da experiência corrente, é substituída pela busca por regularidades e mecanismos testáveis de explicação. Hilary Putnam afirma acerca da postura de Dewey que: "Dewey vê o ser humano como um organismo, que aprende pela única forma possível de se aprender, construindo hipóteses e testando-as na prática" (Putnam, 2000, p. 50). Na medida em que as tentativas de conhecimento se mostram bem sucedidas na prática, elas tendem a ser reforçadas e repetidas, o que favorece a formação de certos hábitos, enquanto enfraquece a formação de outros. Vemos que, para Dewey, o método e os resultados da ciência natural são fundamentais para o método e os resultados da filosofia, e que com isso a experiência é 
"ponto de partida": é um fundamento a partir do qual estruturar a investigação.

A lista de obras do autor é muito vasta, em parte por causa de seu fôlego investigativo, em parte por causa de sua longa carreira produtiva. Neste trabalho, o ponto de partida é a argumentação presente, sobretudo, em $D e$ mocracia e Educação (publicado originalmente em 1916), obra reconhecida como sendo a representação mais detalhada e completa sobre os fundamentos filosóficos envolvidos no tema da educação. A estratégia explicativa ali desenvolvida justifica considerar este texto como o representante dos pontos fundamentais do pensamento filosófico de Dewey.

\section{O princípio de continuidade}

Examinando o discurso desenvolvido por Dewey em Democracia e Educação, pode-se perceber que os quatro primeiros capítulos dedicam-se a um estudo dos princípios mais gerais, a partir dos quais o autor desenvolve os temas que ocupam as demais partes da obra. Estes capítulos podem ser vistos como a base de uma teoria naturalista da educação. O grande princípio, unificador de toda esta teoria é o chamado de "princípio de continuidade". Alguém poderia, sem incorrer em contradição, ensaiar diferentes formulações deste princípio geral, que é o fio condutor de muitas reflexões de Dewey sobre a conduta, a sociedade, a mente, o conhecimento, a comunicação, e no caso que mais importa aqui, a educação. Uma das versões do princípio da continuidade está presente logo no Capítulo 1 desta obra. Ele começa o livro afirmando que: "A mais notável distinção entre as coisas vivas e inanimadas é que as primeiras se mantém pela renovação" (Dewey, 1959, p. 2). Isto não se aplica somente à vida em sentido físico, mas à vida no sentido de experiências, e no que se entende por vida social. Para Dewey, a experiência de um indivíduo, seus hábitos, crenças, sentimentos, se renovam de modo a tornar sua vida possível. Segundo o autor:

O desenvolvimento da biologia, com sua descoberta da evolução confirma esta lição. Pois a significação filosófica da doutrina da evolução reside 
principalmente em pôr em relevo a continuidade das formas orgânicas mais simples e mais complexas até chegar-se ao homem (Dewey, 1959, p. $370)$.

Do mesmo modo ocorre na sociedade: a vida de uma sociedade é justamente o processo de renovação, primeiro dos indivíduos que a integram, e segundo dos modos de agir e pensar, que a definem como tal. A afirmação de que tanto a vida biológica quanto a vida social estão submetidas a mesma regularidade, ao mesmo mecanismo de renovação sem o qual cessariam de existir, é uma das formulações do princípio da continuidade, na filosofia de Dewey.

Para que a vida possa continuar, ela depende de um processo de renovação. Ao logo da vida de um organismo este processo envolve a alimentação, a respiração e todas as outras funções que chamamos fisiológicas. No caso do ser humano, envolve ainda mais, a aquisição de modos de agir e de pensar, como funções comportamentais complexas. Mas a vida ultrapassa os indivíduos, ela prossegue mesmo quando o indivíduo morre, por um processo de replicação segundo o qual os seres vivos individuais geram novas formas de vida semelhantes a eles. As sociedades fazem, segundo Dewey, exatamente a mesma coisa. Uma cultura permanece "viva" por um processo denominável de replicação, e que o autor em sua terminologia chama "transmissão". Esta transmissão torna possível a continuidade da vida das sociedades, a continuidade da experiência humana individual e coletiva, acumulada e passada adiante. Este processo é o que, em linhas gerais, recebe o nome de educação. A educação atende, assim, a uma necessidade da vida na sua forma mais complexa e sofisticada, que é a vida social.

A filosofia moderna é uma filosofia fortemente voltada para a noção de sujeito. A subjetividade tem sido constituída conceitualmente com tanta veemência, que se detecta o aparecimento de uma dicotomia entre sujeito e objeto, entre o mundo interior e o mundo exterior ao sujeito, entre o que é natural e o que é especificamente humano. Boa parte do pensamento contemporâneo tem sido uma tentativa de responder aos impasses causados por esta dualidade estabelecida no pensamento moderno. A atitude filosófica 
que reage contra a filosofia subjetivista da Modernidade, em Dewey, o conduz a pensar o sujeito como um organismo vivo, dotado de impulsos e capaz de adquirir hábitos ou funções de comportamento, e de interagir com o seu meio ambiente, seja ambiente natural ou cultural. Mas a diferença é que na visão de Dewey, o sujeito se faz, de constrói, vem a ser o que é, justamente neste processo relacional em que se modifica ao adaptar-se ao ambiente, e modifica o próprio ambiente. A isso o filósofo denomina de princípio da continuidade, conforme muito bem percebeu Jerome Popp ao afirmar:

A evolução nos mostra que o fenômeno dos seres vivos só é adequadamente explicado em termos da continuidade do crescimento, que é a característica central da teoria. Dewey compreendeu este aspecto dos seres vivos e viu que qualquer análise adequada e avançada da cognição humana deve respeitar o princípio de continuidade, que significa que a mente, a consciência e o conhecimento devem ser descritos na mesma linguagem de mudança contínua exigida para expressar a teoria evolutiva (Popp, 2007, p. $83)$.

Este princípio de continuidade dá integridade e sentido à filosofia da educação de Dewey, em relação harmônica com sua teoria do conhecimento, da sociedade e da conduta. A cultura é um sistema ambiental cujos componentes evoluem, segundo mecanismos de replicação, adaptação e seleção, análogos aos que se impõem aos seres vivos na evolução biológica. A ação intencional dos sujeitos humanos, visando garantir a transmissão com modificação da herança cultural é um dos principais agentes da evolução cultural. Mas seus resultados envolvem aspectos que não se submetem a nenhum esquema determinista de transmissão, pois a comunicação e a experiência humanas seguem percursos de alta complexidade, que ultrapassam o controle dos agentes desta transmissão.

\section{Educação como adaptação}

John Dewey concebe educação como um processo, por meio do qual os indivíduos vêm a tomar parte nos hábitos, crenças e interesses da sociedade de que fazem parte. Mas este processo possui seu fundamento nas estruturas 
desenvolvidas pela espécie humana, por meio das quais o comportamento dos indivíduos permite sua contínua adaptação a um mundo em constante mudança. De um lado, a capacidade de perceber, de atribuir significados e de realizar inferências, é uma estrutura adaptativa que se funda em tendências inatas, e cuja manifestação se dá na esfera individual. Na mesma medida, a educação, ou seja, o processo de transmissão cultural, por meio de uma orientação ou direção das experiências dos membros mais novos de um grupo social é também uma estrutura adaptativa, com a diferença de que sua manifestação, segundo Dewey, se dá na esfera social.

A capacidade cognitiva é desenvolvida no ser humano, como resultado de um longo processo de variação e seleção, em que os organismos vêm tentando se adequar aos seus ambientes. Tanto quanto Dewey vê na idéia de evolução um modo de superar dualidades que só provocam divergências e conflitos no pensamento, ele considera o pensamento como tendo origens naturais. $\mathrm{O}$ pensamento possui função adaptativa em toda a visão que não suponha dois mundos inconciliáveis: o mundo da prática, da experiência, e o mundo da teoria, da subjetividade.

Mas há outro nível além do pensamento do organismo individual. É o nível da linguagem, da transmissão social de significados, da discussão aberta acerca de assuntos comuns. Esta instância é onde se realiza o processo pelo qual os indivíduos mais maduros possibilitam aos mais novos entrar em contato com experiências e situações de aprendizado da vida social de um grupo. E esta instância social do pensamento, tornada possível pelo uso de uma linguagem complexa é, ela mesma, adaptação. Criar um mundo de símbolos, de pensamento representável em linguagem, de cultura transmissível é adaptação.

A pergunta que se tem que fazer é: Qual é o significado de "adaptado" que mais se encaixa na interpretação que aqui se propõe do pensamento de Dewey? Se o indivíduo está adaptado, o que se passa com ele? Ele pode estabelecer objetivos, e lançar mão dos meios mais adequados para atingilos. O que isso quer dizer, segundo Dewey é que 
a criatura viva é uma parte do mundo, aquinhoando de suas vicissitudes e de sua boa-sorte, só conseguindo segurança em sua precária dependência quando se identifica intelectualmente com as coisas que a cercam e prevê as consequências futuras daquilo que está sucedendo, e molda a sua própria atividade de acordo com essa previsão (Dewey, 1959, p. 371).

O indivíduo adaptado é capaz de representar para si um ambiente, e responder adequadamente às situações que surgirem. Isto envolve conhecimento das regularidades e mecanismos, bem como de fatos e eventos, envolve atribuir significados a partir dos quais realizar raciocínios e inferências orientadoras da conduta. Mas, acima de tudo, envolve aprender com os outros, compartilhar significados e readequar a experiência coletiva, disponível na cultura, para seu uso individual.

Além disso, o organismo assim adaptado pode participar efetivamente da formulação e perseguição de objetivos que resultam da comunicação com outros indivíduos, o que ao fim é uma definição de comunidade. Mais que isso, os indivíduos adaptados, no sentido em que se diz que a educação visa à adaptação, são os que vivem em maiores condições de participar da transmissão e da renovação pela qual a própria sociedade vive e evolui. Um indivíduo é tanto mais adaptado quanto mais participa da transmissão e renovação social da vida.

Traduzindo em termos educacionais equivalentes, isto significa: 1) que o processo educativo não tem outro fim além de si mesmo: ele é seu próprio fim; e que, 2) o processo educativo é um contínuo reorganizar, reconstruir, transformar (Dewey, 1959, p. 53).

Estar adaptado, neste caso, não envolve nenhuma versão simplista de "luta pela existência", ou de "sobrevivência do mais forte", onde o indivíduo se equipa com meios para vencer conflitos com seus semelhantes.

Dewey não vê as pessoas como vivendo, ou precisando viver em competição direta, para que a renovação da vida social aconteça. Porque? Por que o ambiente é que determina que tipo de conduta nos torna adaptados ou inadaptados. Em um artigo intitulado "Evolução e Ética" (publicado originalmente em 1898), Dewey já havia deixado claro este ponto. Ele afirma: 
O ambiente é agora distintamente um ambiente social, e o conteúdo do termo 'adaptado' deve ser construído com referência à adaptação social. Mais do que tudo, o ambiente no qual nós agora vivemos é um ambiente mutável e progressivo (Dewey, 1972, p. 6).

A educação em uma sociedade civilizada exige justamente a adoção de uma postura ética, que envolve levar em consideração os interesses dos outros, ou melhor ainda, envolve a comunicação, no sentido mais forte do termo.

Por outro lado, em que condições o indivíduo não poderia ser considerado adaptado? Em que condições é que a educação falha em sua função adaptativa? Quando o indivíduo se mostra incapaz de renovar a si mesmo, a seus hábitos, diante de eventuais mudanças ambientais. Quando, por outro lado, em um ambiente estável, ele sente dificuldade em estabelecer ou formular objetivos que despertem seu interesse, ou de perseguir estes objetivos segundo meios de que possa lançar mão. Além disso, quando sua função comunicativa, sua capacidade de participar do interesse comum é insuficiente para ocasionar o crescimento da experiência de que toma parte.

Finalmente, quando é incapaz de deixar uma herança. O que no sentido de educação, significa ser incapaz de participar de maneira efetiva do processo de renovação da vida social, na comunidade de que faz parte. A tendência a não conseguir transmitir seus hábitos e crenças no ambiente, esta tendência a ter sua identidade cultural substituída por outra que se espalha e transmite mais eficazmente, equivale a estar inadaptado.

Analisando o argumento de Dewey, vemos que ele é uma explicação de como a educação se desenvolve, a partir de necessidades e de estruturas anteriores, mais simples. E que mesmo em sua versão escolar, onde o ensino recebe tratamento profissional, objetivos, métodos e conteúdos bem definidos, ainda assim a educação atende à primordial necessidade de uma relação bem adaptada entre organismo e ambiente. Esta explicação da origem e do processo que resultou na forma de educação observada atualmente na sociedade é, também, um modo de discutir sua eficiência. É um modo de interferir por meio da educação, nas urgências e crises pelas quais uma sociedade passa. Mas o que parece, do ponto de vista do modo como o argumento foi montado, interessar a Dewey neste argumento experimental, é o seu caráter 
dedutivo. O caráter de um modelo com um esquema relativamente simples, mas que pode explicar um fenômeno complexo. Trata-se de uma teoria que, neste sentido, possui a virtude da parcimônia sobre outras teorias possíveis que recorrem a ideais e a evidências de ordem mais especulativa, mais abstrata e, portanto, mais complexa.

O modelo deweyano, segundo o qual a educação promove a adaptação, consiste na aplicação de um recurso que Dennett em A Perigosa Idéia de Darwin descreve muito bem como sendo o recurso a um algoritmo.

Algoritmo é um processo formal no qual se pode confiar - logicamente, que produza uma determinada espécie de resultado sempre que for "posto para funcionar" ou evidenciado (Dennett, 1998, p. 52).

Ora, o processo aqui é aquele segundo o qual os indivíduos estão sempre em busca de tudo o que promove sua melhor adaptação. Transmitir a cultura por meio da comunicação é mais adaptativo para a vida em sociedade do que não transmitir, e o benefício da transmissão é compartilhado por um número significativamente maior de indivíduos. Então, dados os elementos de comunicação dos interesses, vida social carregada de significados, necessidade de tornar públicos e acessíveis aos mais novos os resultados do pensamento para ordenar a conduta, o resultado algorítmico é a educação. Ela é contínua com o acúmulo de complexidade, de significados, de experiência, sem o qual uma sociedade complexa não seria possível. Na verdade, a estratégia evolutiva muito geral, que o ser humano tem tido relativo sucesso em desenvolver nos últimos cento e vinte mil anos envolve justamente reter, acumular, processar e retransmitir a experiência dos membros mais velhos para os mais novos.

Olhar para todo este panorama revelado pela ciência sobre evolução - biológica e cultural - fornece a Dewey a chave para seu argumento. Ele aproveita muito do que já é admitido em domínios conceituais de outras áreas, que mantém relação lógica com o assunto da transmissão cultural. E com isso, se desobriga de ter que construir todo um aparato conceitual abstrato, abrindo flancos para múltiplas hipóteses e possíveis objeções. 


\section{A relação dentre organismo e ambiente}

Dewey estabelece suas idéias sobre a educação, começando o discurso desenvolvido em Democracia e Educação, por uma concepção ambiental do que ocorre com o ser vivo. Segundo esta concepção, nunca se descreve adequadamente o indivíduo sem levar em conta o ambiente onde ele se encontra. A relação ativa de interação constante entre o organismo e o seu ambiente é que torna possível uma descrição compreensível deste organismo individual como um "sujeito". Nisto dewey adere ao método experimental e aos resultados da ciência, frente às concepções especulativas que vinham sendo mantidas pelo pensamento tradicional.

Dewey adota, ao lançar a base de sua filosofia da educação, uma concepção do ser humano e da cultura, marcada profundamente pela consideração de aspectos ambientais. Esta concepção situa o organismo em contínua relação com seu meio ambiente. A própria noção de sujeito resultante deste pensamento, opõe-se à noção tradicional, de um sujeito dado, fundante, constituído como uma substância dotada de razão e vontade, condição inicial de qualquer reflexão teórica. Dewey substitui esta noção substancial por uma noção relacional do sujeito, ou indivíduo, na qual algumas distinções fixas, presentes no pensamento moderno se dissolvem, dando lugar a processos e funções em constante transformação e troca simultânea. É o caso da relação entre mente e corpo, bem como da relação entre organismo e meio, assim como da relação - talvez mais conhecida do público - entre teoria e prática.

Na educação, Dewey dá especial atenção ao desenvolvimento do pensamento individual e ao envolvimento do indivíduo por meio do interesse real nas atividades e experiências que lhe são propostas. Segundo o autor, é esta a diferença que existe entre a genuína educação - uma capacidade própria da espécie humana - e o adestramento - aplicável a muitos outros animais. É que, para Dewey, a educação envolve participação em interesses comuns. O outro, o interlocutor, o comunicador, é a parte mais importante do meio ambiente da cultura. A linguagem cria este espaço comum de valo- 
res compartilhados. O elo da comunicação, da representação, é muito mais profundo do que a mera proximidade ou contigüidade física. Conhecer os pensamentos do outro é que estabelece este laço. Toda adaptação tipicamente humana envolve em alguma medida nossa maior invenção: a linguagem. Daniel Dennett afirma acerca dela:

A capacidade de linguagem, sem dúvida, é a maior realização da evolução, uma realização que se nutre a si mesma para produzir sistemas racionais ainda mais versáteis e sutis; mas ela pode ainda ser vista como uma adaptação que está sujeita às mesmas condições de utilidade ambiental, como qualquer outro talento comportamental (Dennett, 2006, p. 49).

Ou seja, a linguagem, como um artefato, ao auxiliar os seres humanos em seu processo de comunicação, socialização e, portanto de evolução, também está sujeita a alterações, seleções e modificações, tanto quanto as crenças, idéias e significados que, por meio da linguagem, os seres humanos comunicam. Menciona-se Dennett porque, embora não tenha se devotado, como Dewey, aos temas da educação, suas concepções filosóficas acerca de conhecimento, linguagem e transmissão cultural são muito próximas, a ponto de Dennett poder ser incluído na continuidade da tradição naturalista iniciada no início do século XX por John Dewey.

Para Dewey, há continuidade entre os efeitos do adestramento e da educação. Deve, contudo, haver um modo de operar claramente a distinção. Esta distinção consiste na participação no interesse social relacionado à atividade. A linguagem pela qual o pensamento pode ser representado, e a experiência de uns indivíduos estar disponível a outros, é o instrumento fundamental, o veículo, o suporte sem o qual este processo não é possível. A educação é a promoção de um genuíno interesse social pelas próprias condições experimentais em que se realiza. E a educação assim entendida envolve certa noção de intencionalidade, condição necessária de toda comunicação.

A etapa seguinte seria o indivíduo assumir uma atitude objetiva e levar em consideração os outros com quem forma um grupo social, assim se integra nas práticas comuns e desenvolve interesses comuns. Por isso o adestramento é o estágio inicial de um processo de formação de hábitos cujo estágio mais complexo é o que Dewey chama propriamente educação. Algo 
de que, sem a linguagem, e sem o pensamento intencionalmente conduzido, com a finalidade de estabelecer contato entre o meu comportamento e o dos outros, nenhum indivíduo é capaz. Temos, assim, para a educação poder acontecer, a ação coordenada de três processos: a) comunicação como participação nos significados e elementos da experiência; b) estabelecimento de objetivos, visando a relação integrada, ou adaptada, com um meio ambiente, e c) pensamento reflexivo.

Os processos de transmissão precisam ocorrer em harmonia com os processos experimentais, decorrentes da experiência social e que só têm sentido como integrantes desta mesma experiência. As ações políticas no campo democrático, assim como as ações epistemológicas e educacionais no campo do pensamento reflexivo e da investigação experimental, têm como meta, como objetivo maior, produzir condições de continuidade e evolutibilidade do próprio crescimento e reconstrução da vida como um todo. "Vida" significando a relação complexa e em constante fluxo, da adaptação de um organismo ao seu ambiente, e vice-versa.

Uma concepção adaptacionista resulta do apelo à ciência, vista como método ou disciplina intelectual, como um conhecimento que - baseado na experiência - é capaz de proporcionar os materiais adequados para a reconstrução da educação e da filosofia. A argumentação em favor de que o conhecimento só é transmitido indiretamente, através do meio, reforça a existência relativamente independente de um ambiente cultural, dotado de regularidades inerentes, e que se modifica e desenvolve em um processo constante. Processo sobre o qual o ser humano, mesmo sem a intenção formalizada, é capaz de interferir.

O meio ambiente consiste na soma total das condições necessárias para a realização das atividades características de um ser vivo. O meio social consiste em todas as atividades de seres semelhantes intimamente associados para a realização de seus fins comuns (Dewey, 1959, p. 24).

A educação se realiza por meio da direção da atividade do outro, não direta mas indiretamente, mediante a seleção de condições da experiência individual. Esta direção é uma seleção, como se disse, que afeta as variações que 
terão maior ou menor disseminação no ambiente da cultura. A direção feita pela educação manifesta uma intencionalidade (desígnio): a de "auxiliar, por meio da cooperação, as aptidões naturais dos indivíduos guiados" (Dewey, 1959, p. 25). Em ouras passagens encontramos o termo "cultivo", tornando ainda mais clara a comparação com a manipulação feita pelos agricultores e criadores, quanto às condições de crescimento das espécies por eles criadas. Assim como o educador manipula as condições de crescimento, não do indivíduo exatamente, embora esta seja uma forma possível da metáfora, mas mais do que isso, das condições a que se submetem as espécies de hábitos, crenças e atitudes que estão sendo cultivadas no ambiente da cultura. O que não se pode deixar de perceber, para que a alegoria faça sentido, é que os hospedeiros destes hábitos, crenças e atitudes, são os indivíduos, sobre quem a ação educativa não se exerce de modo direto, mas pelo cultivo ou seleção de diferentes tipos de hábitos, diferentes modos de experiência, diferentes situações.

O fator de indeterminação envolvido na educação, e no caso mais amplo, no processo de transmissão da vida social como um todo, reside justamente aqui: é que, ao interferir no ambiente social, por meio da ação pedagógica, se está criando condições de novas experiências. O objetivo declarado é a formação de certos hábitos. Entretanto, ela acaba por não incidir diretamente no organismo, o que é impossível, já que o organismo sempre filtra, atribui significados, responde aos estímulos, e por outro lado o professor, a matéria lecionada e a própria escola não são mais do que partes, mesmo que especiais, do ambiente. Então, é possível que esta modificação ambiental que é a educação, uma vez que envolve o concurso de inúmeros fatores sociais, lingüísticos, e mesmo fatores físicos, dê condições favoráveis ao desenvolvimento de respostas na forma de hábitos diversos dos inicialmente esperados pelo educador. A "reprodução" de hábitos, crenças e valores, como toda reprodução, dá origem a variações, que tendem a aparecer em número cada vez maior, em razão, entre outras coisas, da maior mudança ambiental. 


\section{O desafio da diversidade}

Aqui alguém poderia formular a seguinte objeção: Um ambiente cultural mais complexo e mais variado, e com mais conteúdo simbólico, não acarretaria uma maior dificuldade de adaptação dos indivíduos? Ela se manifestaria, por exemplo, na maior distância entre as capacidades inatas dos jovens ${ }^{1}$ e o interesse social nas atividades dos adultos. Ou então na exigência de cada vez mais direção e controle, mais esforço educativo e pressão social sobre a plasticidade juvenil, a fim de forjar hábitos que o adaptem ao ambiente social altamente complexo. Assim, mais complexidade significaria mais educação, mas também menos adaptação.

Este parece, em primeiro lugar, ser um problema de que sofre somente o modelo de educação tradicional. A meta da educação, tal como Dewey concebe, não é transmitir ao indivíduo todo o legado do passado, toda a cultura acumulada, por meio discursivo. A educação seleciona os hábitos que permitem a vida adaptada naquele estágio particular da vida social, juntamente a preparação para as eventuais mudanças ambientais. $\mathrm{Na}$ medida em que novos hábitos vão sendo introduzidos por causa da mudança cultural no ambiente, alguns são extintos, caem em desuso, tornando desnecessário investir energia em processos educativos para desenvolvê-los. Os hábitos que têm crescido gradativamente em importância, nas sociedades humanas mais complexas, são aqueles que envolvem o pensamento reflexivo e a comunicação. A causa da retenção e dispersão destes hábitos não é nenhuma vantagem intrínseca, nenhum valor abstrato, senão que eles permitem a adaptação a um ambiente formado cada vez mais por símbolos, onde é essencial o processamento veloz e eficiente das informações.

Há duas saídas para o impasse em que nos encontramos por acompanhar o argumento de Dewey na direção da educação como adaptação, no caso de ambientes que crescem rapidamente em complexidade: i) a divisão da educação em conjuntos especializados de hábitos, por meio de procedimentos mais rigorosos de seleção intencional, e ii) a diversificação das

\footnotetext{
${ }^{1}$ Dewey utiliza o termo "imaturo", mais familiar em seu contexto.
} 
crenças e dos hábitos, por meio de uma seleção que amplie a diversificação. Em uma delas, a educação dirigir-se-ia a públicos com funções sociais distintas, enfocando somente aqueles que são adaptativos a papéis sociais prédeterminados. Porque, já que há muito que transmitir, dividir-se-ia a transmissão segundo um critério funcional dos indivíduos. Mas esta saída é, para Dewey, completamente contraditória com a necessidade de variação, de mudança, de novidade constante. É uma saída completamente contrária ao princípio de continuidade.

Dewey fundamenta toda a sua filosofia da educação na suposição de que o indivíduo é capaz de, por uma percepção de sua situação experimental, modificar e enriquecer esta própria situação com novos significados. O crescimento permite mais crescimento, e este é o valor, o objetivo, a meta, que não está condicionada a nenhuma outra.

O aprender a prática de um ato, quando não se nasce sabendo-o, obriga a aprender-se a variar seus fatores, a fazer combinações destes, de acordo com a variação de circunstâncias. E isso traz a possibilidade de um contínuo progresso, porque, aprendendo-se um ato desenvolvem-se métodos bons para outras situações. Mais importante ainda é que o ser humano adquire o hábito de aprender. Aprende a aprender (Dewey, 1959, p. 48).

A diversidade é resultante da própria capacidade de aprendizagem e, portanto, já que o crescimento e a diversidade experienciais são inevitáveis, devem se encorajados, ampliados, alimentados, cultivados. A diversidade, que parece ser considerada por Dewey um traço a ser encorajado na educação moral, é esta descrita na segunda saída.

Mas ainda se poderia perguntar: A comunicação, como participação no interesse comum envolvido em atividades com significado social, por sua vez, não seria infensa a tal diversidade, pela qual membros de distintos grupos nada teriam que permitisse a comunicação entre si? Afinal, a evolução cultural tem que envolver especiação, como isolamento entre conjuntos de hábitos a tal ponto que se romperia o laço de transmissibilidade, ou replicabilidade. Mas a resposta aqui, segundo Dewey, seria que não é necessário pensar que se rompa a cooperação no ambiente e a mútua consideração dos interesses entre diferentes sistemas, ou espécies de hábitos. Assim como 
diferentes espécies de seres vivos cooperam a fim de atingir objetivos que contribuem para o crescimento e a transmissão da vida, também membros de diferentes grupos sociais, e detentores de diferentes sistemas de hábitos, podem descobrir maneiras de se adaptar uns aos outros, e se beneficiar da diversidade para o mútuo crescimento e a máxima transmissão de sua experiência. A comunicação não necessariamente pressupõe unidade nem uniformidade, muito pelo contrário. A diversidade parece mais ampliativa, no sentido de permitir mais variações de comportamentos, de significados e de comunicação, que podem vir a ser selecionadas, ou pelos indivíduos ou pelos próprios ambientes, no processo de adaptação entre uns e outros.

\section{Conclusão}

Argumentou-se no sentido de mostrar que a educação e a adaptação ao ambiente são, para Dewey, processos profundamente interdependentes. Ambos são aqui compreendidos segundo o princípio de continuidade da natureza, segundo o qual todo organismo tem a necessidade incontornável de estabelecer uma relação bem adaptada com o seu ambiente. No caso do ser humano, particularmente, o ambiente social. A formação dos hábitos que permitem posterior crescimento e constante adaptabilidade dos indivíduos, que é dada na educação, envolve, com especial razão, os hábitos de conduta reflexiva e comunicativa, pelos quais o indivíduo participa e se integra ao ambiente comum, público, que é a cultura em uma das acepções do termo.

Por causa disso, por meio de processos mais eficientes e bem sucedidos de educação, não são somente os indivíduos que se modificam para se adaptar ao ambiente, mas o próprio ambiente se modifica, numa relação de mão dupla. Educação que permita aos indivíduos ocasião de desenvolver hábitos mais eficazes de comunicação, compreensão das intenções e pensamentos dos outros, e participação no processo público de reconstrução de crenças, artefatos e valores, tem como resultado a própria evolução da cultura segundo a seleção de seus principais componentes: crenças, artefatos e valores. 
A educação, então, compreendida neste sentido, encontra mais ocasiões de se realizar do que aquelas esperadas e planejadas somente nos espaços institucionais formais. Além disso, estas próprias ocasiões formais, ao se estabelecerem sobre objetivos e métodos alheios e estranhos às necessidades dos indivíduos, no processo de reconstrução constante da vida, podem vir a ser ocasiões de tediosa e enfadonha experiência deseducativa, promovendo a proliferação no ambiente da cultura, de hábitos e valores que impedem, ao invés de favorecer, o crescimento posterior.

Caberia à pesquisa e ao debate rigoroso e orientado segundo os métodos mais criteriosos de pensamento e experimentação, em constante diálogo com as diversas áreas de investigação científica, procurar planejar e desenvolver mecanismos segundo os quais, pela educação, se poderia convenientemente interferir de modo favorável nos mais elevados objetivos individuais e sociais dos indivíduos, ao longo do processo complexo e acelerado de evolução cultural.

Lembrando que, no fim de contas, esta evolução, embora possa ser parcialmente afetada pelo propósito humano, não o pode ser totalmente. $\mathrm{O}$ risco para os indivíduos é que a negligência quanto ao aspecto evolutivo presente de modo inexorável na educação, possa conduzir a direções opostas à obtenção dos objetivos que estabelecemos como importantes e válidos.

\section{Referências}

DEWEY, John. (1924). Democracia e educação: introdução à filosofia da educação. 3. ed. Tradução Godofredo Rangel e Anísio Teixeira. São Paulo: Cia Editora Nacional, 1959.

"Evolution and Ethics". In: The Early Works of John Dewey 1882-1898, Vol. 5 (1895-1898). Jo An Boydston (Ed.). Carbondale \& Edwardsville: Southern Illinois University Press. 1972.

. Textos Selecionados. In: Os Pensadores. São Paulo: Nova Cultural. 1974.

DENNETT, Daniel. A Perigosa Idéia de Darwin. Rio de Janeiro: Rocco. 1998. . Brainstorms. São Paulo: Ed. Unesp. 2006. 
LORENZ, Konrad. A demolição do homem - crítica à falsa religião do progresso. São Paulo: Brasiliense. 1986.

POPP, Jerome. Evolution's First Philosopher - John Dewey and the Continuity of Nature. Albany: State of New York Univ. Press. 2007.

PUTNAM, Hilary \& PUTNAM, Ruth. "Educação para a Democracia. In: GHIRALDELLI, Paulo (org.). Estilos em Filosofia da Educação. Rio de Janeiro: DP\&A. 2000.

SANTAYANA, Georges. "Dewey's Naturalistic Metaphisics" (p. 243-262). In: The Library of Living Philosophers - The Philosophy of John Dewey. Chicago: Northwestern University, 1939. 